\title{
Research on the best loan-to-value ratio of inventory financing based
}

\author{
on credit risk
}

\author{
Yili Su, Fuchang Li, Guichang Zhe ${ }^{*}$, Xiaohui $\mathrm{Hu}$ \\ School of Economics \& Management, Yunnan Normal University, Kunming, China \\ *Corresponding author: Guichang Zhe ,fuchanglikt@126.com
}

\begin{abstract}
The loan-to-value ratio is the key to decide bank facing different degree of credit risk, which directly affect the profitability of the bank. In order to avoid bank’s losses accused by inventory financing due to credit risk, this paper chooses the loan-to-value ratio as the research object supposed that Credit risk events follow Poisson distribution. By the model construction, the bank can get best ratio under different credit risk. The research results provide important practical significance for bank to make decisions about the best loan-to-value ratio in the inventory financing business of the loan enterprises.
\end{abstract} Keywords: credit risk; inventory financing; lending decisions

\section{Introduction}

In the bank's inventory pledge business, the most common is the credit risk occurred between banks and borrowing enterprises. Therefore, the choice of loan-to-value ratio is not only beneficial for banks to make the best choice based on the expected profit maximization, but also can effectively help SMEs overcome financial difficulties. From the perspective of financing loans, which focuse on credit risk, a static inventory rate model with credit risk is established, which focuses on how to make the decision of loan-to-value ratio under different credit risks. The goal is to effectively reduce the credit risk of the banks in the inventory financing business, and to improve banks' achievement.

For the Study on the loan-to-value ratio, both domestic and foreign scholars have provided different research ideas, mainly divided into two major ideas: Structural thinking and simplified thinking. Li Yixue and Feng GengZhong (2007) ${ }^{1}$ studied the mortgage rate decision problem of banks with downside risk aversion when the final price of pledged inventory follows the general distribution and several specific distributions. $\mathrm{Xu} Y \mathrm{Yu}, \mathrm{Li} \mathrm{Yi}, \mathrm{Li}$ Juan, et al. (2007) ${ }^{2}$ assumed that the probability of default follows Poisson distribution, and 
studied expected return on pledged inventory and influence of price fluctuation on the loanto-value ratio with a structural thinking. Sun Zhaoyuan and Wei Yan (2011) ${ }^{3}$ assumed that Price change of portfolio pledge inventory under Static pledge mode is mutually independent and it obeys the lognormal distribution, under this hypothesis, it constructed decision-making model of loan-to-value ratio and analyzed its influencing factors. Wang Hua $(2015)^{4}$ took loan-to-value ratio as the research object, adopted loan-to-value ratio model under different mortgage modes by model construction. Among them, the author adopted the simplified idea, set the default probability as a constant, then got the best loan-to-value ratio.

Based on the above scholars' researches, from the angle of using credit rating to consider the financing loan, the possible credit risk is regarded as the Poisson distribution, which is close to the reality, and established the inventory loan-to-value ratio model based on credit risk. Last, focusing on the expected return and volatility on the ending price of stocks v the credit rating index $\theta$, and default times $\mathrm{h}$ respectively are how to influence loan-to-value ratio in inventory financing business. In view of the above research ideas: the following assumptions are proposed:

Hypothesis 1: banks have a full credit rating system, and the credit rating index $\theta$ is divided into four grades, namely 1,2,3,4. both the bank and the borrower are risk neutral.

Hypothesis 2: under static pledge mode for the inventory financing business, the bank has complete closed account.so at the end of the inventory financing period, if there is no credit risk, loan companies directly transfer Inventory capital on sale into closed accounts; if there is credit risk of default, the borrower cannot repay loans, Assuming a default event (credit risk) as an event $\mathrm{A}$, which obeys Poisson distribution, namely $A$ : $p(\theta)$.

Hypothesis 3: in the case of credit risk, the borrower either choose additional margin to make up the difference with probability $e^{-\theta}$; or choose default with probability $p(\theta) \cdot p(\theta)$ is default probability of the borrowing Enterprises, namely inventory $Y: \quad p(y=h)=e^{-\theta} \frac{\theta^{h}}{h !}, h=0,1 \ldots$

if $h=0, \quad p(y=0)=e^{-\theta}$, it Indicates that the default event did not occur, with no credit risk. Hypothesis 4: at the beginning of inventory pledge period, Inventory $\mathrm{Y}$ as collateral, which can be used to transact inventory financing. Granting Initial market price、 Quantity of inventory $\mathrm{X}$ as $p_{0} 、 m$; Inventory pledge period or loan maturity as $\mathrm{T}$, Based on the initial market price as a reference, the bank will set loan-to-value ratio of inventory's unit value as $\tau$, so the loan amount of the loan enterprise shall be $\tau m p_{0}=\tau \gamma$, in which, $\gamma=m p_{0}$ is the initial market value of inventory. 
Hypothesis 6: At the end of the inventory financing period, assuming that the price $p_{T}$ of $\mathrm{Y}$ follows lognormal distribution, namely $\ln p_{T} \sim N\left(u_{T}, \delta_{T}{ }^{2}\right), \mu_{T}, \delta_{T}$ are respectively logarithmic yield and logarithmic volatility of the final price, the desired value of Final market price is $E\left(p_{T}\right)=e^{\left(\delta_{T}{ }^{2} / 2\right)_{+} \mu_{T}} \quad$, and standard deviation is $\sqrt{D\left(p_{T}\right)}=\sqrt{\left(e^{\delta_{T}^{2}}-1\right) e^{\delta_{T}^{2}+2 u_{T}}}$, $f_{p_{T}}(y)=\frac{1}{\sqrt{2 \pi} y \delta_{T}} \exp \left[-\frac{1}{2}\left(\frac{\ln y-u_{T}}{\delta_{T}}\right)^{2}\right], F_{p_{T}}(y)$ is corresponding probability distribution function.

\section{Model constructions}

At the end of inventory financing, two cases may occur in the model. first case: if the Y's value is higher than capital and interest of inventory financing, namely $p_{T} m>\left(1+r_{2}\right)^{T} \tau p_{T} m$, then concluded $p_{T}>\left(1+r_{2}\right)^{T} \omega p_{0}$.in this case, The borrower is able to repay the bank's loan by selling inventory $\mathrm{Y}$ for obtaining funds with market price $p_{T}$, so the final profit of bank's inventory financing business can be expressed as follows: $\Pi(\tau)=\left[\left(1+r_{2}\right)^{T}-\left(1+r_{1}\right)^{T}\right] \tau p_{0} m$. The second case: if the Y's value is lower than capital and interest of inventory financing. Namely $p_{T} m \leq\left(1+r_{2}\right)^{T} \tau p_{T} m$, then concluded $p_{T} m \leq\left(1+r_{2}\right)^{T} \tau p_{0} m$.therefore, the borrower have two options, one is default with probability $p(\theta)$, bank's profit led by default is $\Pi(\tau)=\left[p_{0}-\left(1+r_{1}\right)^{T} \tau p_{0}\right] m$. conversely, Another option is to comply with the agreement, its probability is $e^{-\theta}$, in this case, bank's profit is $\Pi(\tau)=\left[\left(1+r_{2}\right)^{T}-\left(1+r_{1}\right)^{T}\right] \tau p_{0} m$.

In summary, we can obtain the expected profit of the bank as:

$$
\begin{aligned}
& E[\Pi(\tau)]=\left[\left(1+r_{2}\right)^{T}-\left(1+r_{1}\right)^{T}\right] \tau m p_{0} \int_{\tau p_{0}\left(1+r_{2}\right)^{T}}^{+\infty} f_{p_{T}}(y) d y \\
& +\left[\left(1+r_{2}\right)^{T}-\left(1+r_{1}\right)^{T}\right] \tau p_{T} m e^{-\theta} \int_{0}^{\tau p_{0}\left(1+r_{2}\right)^{T}} f_{p_{T}}(y) d y \\
& +\left(e^{-\theta} \frac{\theta^{h}}{h !}\right) \int_{0}^{\tau p_{0}\left(1+r_{2}\right)^{T}} m f_{p_{T}}(y)\left(y-\tau p_{0}\left(1+r_{1}\right)^{T}\right) d y
\end{aligned}
$$




$$
\begin{aligned}
& =\left[\left(1+r_{2}\right)^{T}-\left(1+r_{1}\right)^{T}\right]\left(1+e^{-\theta}\right) \tau m p_{0}+ \\
& m\left(e^{-\theta} \frac{\theta^{h}}{h !}\right) \int_{0}^{\tau p_{0}\left(1+r_{2}\right)^{T}} f_{p_{T}}(y)\left(y-\left(1+r_{2}\right)^{T} \tau p_{0}\right) d y \\
= & {\left[\left(1+r_{2}\right)^{T}-\left(1+r_{1}\right)^{T}\right]\left(1+e^{-\theta}\right) \tau m p_{0} } \\
- & \left(e^{-\theta} \frac{\theta^{h}}{h !}\right) \int_{0}^{\tau p_{0}\left(1+r_{2}\right)^{T}} m F_{p_{T}}(y) d y
\end{aligned}
$$

So we can get the inventory loan-to-value ratio model:

$$
\begin{aligned}
& \max _{\tau} E[\Pi(\tau)]=\left[\left(1+r_{2}\right)^{T}-\left(1+r_{1}\right)^{T}\right]\left(1+e^{-\theta}\right) \tau m p_{0} \\
& -\left(e^{-\theta} \frac{\theta^{h}}{h !}\right) \int_{0}^{\tau p_{0}\left(1+r_{2}\right)^{T}} m F_{p_{T}}(y) d y, \\
& \text { s.t } 0<\tau<1
\end{aligned}
$$

Among them, the occurrence of inventory Y's default or credit crisis events, as the event A, which subject to Poisson distribution, namely $A$ : $p(y=h)=e^{-\theta} \frac{\theta^{h}}{h !}, h=0,1 \ldots$ In addition, the Y's final price follows lognormal distribution, namely $\ln p_{T} \sim N\left(u_{T}, \delta_{T}^{2}\right), f_{p_{T}}(y)=\frac{1}{\sqrt{2 \pi} y \delta_{T}} \exp \left[-\frac{1}{2}\left(\frac{\ln y-u_{T}}{\delta_{T}}\right)^{2}\right]$ is the probability density function, $F_{p_{T}}(y)$ is corresponding distribution function.

From the above research hypothesis and model analysis, this paper concludes the best loan-tovalue ratio $\tau^{*}$ based on banks' profit maximum:

$$
\tau^{*}=\frac{e^{\delta_{T} z_{\phi}+u_{T}}}{\left(1+r_{2}\right)^{T} p_{0}}
$$

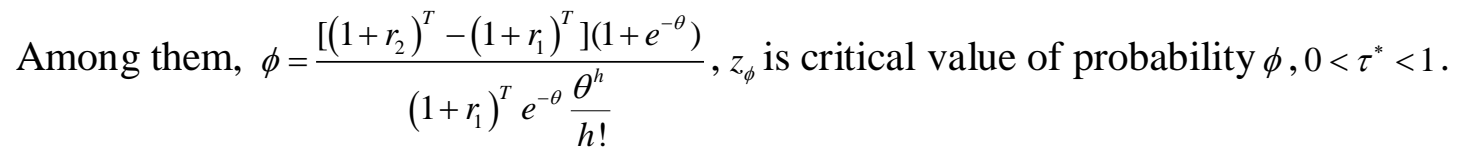

From the above static inventory loan-to-value ratio model based on credit risk, Under the assumption that the credit risk event obeys Poisson distribution and the final inventory price follows the normal distribution, banks can set up the best loan-to-value ratio according to different credit levels of borrowing ventures, so as to maximize the expected profits of the banks 


\section{Conclusions}

This paper analyzes the choice of loan-to-value ratio for the different levels of credit risk .We can draw the following conclusions from the model: With Logarithmic yield and Logarithmic volatility increase, The best loan-to-value ratio will increase accordingly; The impact of default events on the best loan-to-value ratio is as follows: Consider it as a whole, with PD of borrowing ventures increase, bet the best loan-to-value ratio will decrease; Concrete influence: With the increase of credit rating index of loan enterprises, The best loan-to-value ratio will decrease; As the number of defaults gradually increase, The best loan-to-value ratio increases accordingly.

\section{Acknowledgement}

The authors greatly appreciate the anonymous referees and the associate editor for their very valuable and helpful suggestions on an earlier version of the paper. This research is supported by the NSF of China (Grant No. 71362028, 71562036), Applied Basic Research Project of Yunnan Province(Grant No.2015FB142), Youth Leaders Project in Academic and Technical of Yunnan Province (Grant No.2014HB009), and Yunnan Provincial Doctoral Discipline Construction Planning (Applied Economics).

\section{References}

1. Y. X. Li, G. Z. Feng, Y. Xu, Research on Loan-to-value Ratio of Inventory Financing under Randomly- fluctuant Price [J], System engineering theory and Practice, 2007, 27(12):42-48.

2. Y. X. Li, Y. Xu, G. Z. Feng, F. Wang, On Loan- to- Value Ratios of Inventory Financing with Doubly Stochastic Poisson Default Processes [J], Chinese Journal of Management Science, 2007,15(2):21 26.

3. C. Y. Sun, Y. Wei, Research on Loan- to- Value Ratio of Double Category Inventory Financing[J],Finance \& Economics, 2011, 2011(10):117-124.

4. H. Wang, Research on the loan-to-value ratio model of inventory and inventory portfolio which based on the different modes of pledge [D], Yunnan Normal University, 2015. 